\title{
Outbreak
}

\section{Evaluation of the increase in invasive device associated infections in cardiovascular surgical intensive care unit}

\author{
Esra Kaya Kılıç ${ }^{1}$, Cemal Bulut ${ }^{2}$, Muzaffer Çeliköz ${ }^{3}$, Günay T Ertem ${ }^{1}$, Çiğdem Ataman Hatipoğlu ${ }^{1}$, Meliha \\ Çağla Sönmezer ${ }^{1}$, Sami Kınıklı ${ }^{1}$, Salih Fehmi Katırcıoğlu ${ }^{3}$ \\ ${ }^{1}$ Department of Infectious Diseases and Clinical Microbiology, Ankara Training and Research Hospital, Ankara, \\ Turkey \\ ${ }^{2}$ Department of Infectious Diseases and Clinical Microbiology, Gülhane Training and Research Hospital, Ankara, \\ Turkey \\ ${ }^{3}$ Department of Cardiovascular Surgery, Ankara Training and Research Hospital, Ankara, Turkey
}

\begin{abstract}
Introduction: Infections related to the use of invasive instruments leads to the risk of treatment difficulties, prolonged hospitalization, increased health care costs, and increased mortality and morbidity rates. The present study examines the results of an infection surveillance study that showed an increased incidence of infections related to the use of invasive instruments in the cardiovascular surgery intensive care unit of the Ankara Training and Research Hospital and mitigating measures were taken following the surveillance program.

Methodology: Compared with previous surveillance data, an increase was observed in the incidence of infections related to the use of invasive instruments in cardiovascular surgery intensive care unit (CVS-ICU) during the first six months of 2014. A research team was formed comprising one infectious diseases and microbiology specialist, one cardiovascular surgeon, and two infection-control nurses. Patient data was collected. The compliance of the surgeons, nurses, and other health care professionals to the infection control measures was evaluated.

Results: The rate of ventilator-associated pneumonia was $8.20 \%$ and the rate of catheter-associated urinary tract infection was $4.47 \%$ in the CVS-ICU. There were missing or inadvertent practices regarding antibiotic prophylaxis, asepsis and antisepsis and isolation measures in patient preparation and patient care before and after the operations. The rate of inappropriate antibiotic as prolonged use was $72 \%$.

Conclusions: It is one of the basic tasks to take appropriate measures to prevent outbreaks of hospital infections. It is possible to prevent an outbreak of hospital infections only by the accurate analysis of data and establishing strict infection control procedures.
\end{abstract}

Key words: Outbreak; intensive care unit; invasive device associated infections.

J Infect Dev Ctries 2018; 12(7):508-513. doi:10.3855/jidc.10012

(Received 04 Deccember 2017 - Accepted 22 March 2018)

Copyright (C) 2018 Kaya Kılıç et al. This is an open-access article distributed under the Creative Commons Attribution License, which permits unrestricted use, distribution, and reproduction in any medium, provided the original work is properly cited.

\section{Introduction}

Infections are common in intensive care units and constitute a significant problem in hospitals. Hospitalacquired infections result in increased health care costs, due to prolonged hospitalization, and increased mortality and morbidity rates [1]. Many factors play a role in the development of infections following cardiovascular surgery (CVS), including prolonged hospitalization before surgery, inappropriate prophylaxis, inadequate compliance to asepsisantisepsis procedures, length of stay in the intensive care unit after surgery, prolonged intubation time, etc [2-7]. Patients bearing many of these factors require intensive surveillance programs to be established in order to prevent postoperative infections [2]. In this study we focused on device-related infections, which are infections that can be prevented; therefore, they are particularly important in the intensive care units' environment. Although there is very limited information regarding the effects of specific infection control programs on the prevention of postoperative infections, the emergence of new outbreaks further complicates these programs.

The present study examines the surveillance studies, measures taken, and the outcomes of mitigating measures following the emergence of an infection with epidemic potential in the cardiovascular surgery intensive care unit at the Ankara Training and Research Hospital.

\section{Methodology}

An increase in invasive instrument-related infections was reported in the cardiovascular surgery intensive care unit (CVS-ICU) following operations 
conducted in the cardiovascular surgery theatre during the first six months of 2014. The infection rates in the other surgical theatre and intensive care units were also evaluated. This was followed by an assessment of the current situation and the necessary measures required. The study data was retrospectively collected by reviewing patient charts and the surveillance data from the infection control committee for 2013 and the first six months of 2014.

Patients who were connected to ventilator support after surgery were diagnosed with Ventilator-associated pneumonia (VAP) if there was the presence of fever, increased lung secretions, recent infiltration and/or increase in infiltrative appearance on a chest $x$-ray, and bacterial growth $>105 \mathrm{cfu} / \mathrm{mL}$ in deep tracheal aspirate culture. Catheter-associated urinary tract infection (CAUTI) was identified in patients who had a urinary catheter in place and developed fever, pyuria and had bacteria $>105 \mathrm{cfu} / \mathrm{mL}$ in urine cultures. Central venous catheter-associated infection in the bloodstream (CVCA-BI) was identified by increased bacterial growth in central line blood cultures in comparison to a blood culture from another vein site. Rates of VAP, CAUTI, and CVCA-BI and causative agents observed in the department of cardiovascular surgery were identified in this study.

A research team, comprising of an infectious diseases and clinical microbiology specialist, a cardiovascular surgeon, and two infection-control nurses, conducted visits at different time points to the operating theatre, intensive care unit and ward of the department of cardiovascular surgery, without giving prior notice, in order to assess the current situation and practices in place. Routine procedures in the ward, operating theater, and intensive care unit were subsequently reviewed. Environmental samples were collected from predetermined locations and instruments in the operating theatre, as the operating table, sterile surgical instruments and aspirator. A report was prepared detailing inappropriate practices observed during the visits and suggestions for mitigating measures. The report was submitted to the hospital administration and relevant clinical and education programs were planned in order to improve practice.

The research team observed the preparation of patients for surgery, the compliance of personnel to hand hygiene, the use of personal protective equipment, barrier measures, asepsis-antisepsis during catheter insertion and maintenance, and wound dressing. From these observations, incorrect practices were determined. The research team continued monitoring the hospital infection rate in the department of cardiovascular surgery.

\section{Results}

The invasive instrument-associated infection rates reported in the CVS-ICU of the Ankara Training and Research Hospital during 2014 by surgeons, and the type of invasive instrument-associated infection, are shown in comparison to previous years in Table 1 . The quarterly distribution of infection rates in 2014 and the rates documented following the implementation of educations programs and mitigation measures are shown in Table 2. Three patients with VAP and one patient with wound site infection were concurrently hospitalized in a six-bed intensive care unit. Of the patients diagnosed with VAP, two also had urinary tract infections. Different microorganisms were isolated from the infected patients (Table 3).

Site visits were conducted in different time frames to the operating theatre, intensive care unit and regular ward of the department of cardiovascular surgery. These visits revealed that the shaving of the surgical site as part of the operative preparation was performed one day before surgery in patients hospitalized in the regular ward and 18 hours before surgery in patients hospitalized in the intensive care unit. It was noted that antibiotic prophylaxis with cefazolin $1 \mathrm{~g}$ was initiated intravenously on admission and continued until discharge from the hospital. Cefazolin prophylaxis was

Table 1. Yearly distribution of invasive instrument-associated infection rates in CVS-ICU.

\begin{tabular}{ccccccccc}
\hline Years & $\begin{array}{c}\text { Number of } \\
\text { patients }\end{array}$ & $\begin{array}{c}\text { Total days in } \\
\text { hospital }\end{array}$ & $\begin{array}{c}\text { Ventilator } \\
\text { utilization } \\
\text { rate* }\end{array}$ & $\begin{array}{c}\text { Infection } \\
\text { Rate of } \\
\text { VAP** }\end{array}$ & $\begin{array}{c}\text { Urinary } \\
\text { catheter } \\
\text { utilization } \\
\text { rate* }\end{array}$ & $\begin{array}{c}\text { Infection } \\
\text { Rate of CA- } \\
\text { UTI*** }\end{array}$ & $\begin{array}{c}\text { CVC } \\
\text { utilization } \\
\text { rate* }\end{array}$ & $\begin{array}{c}\text { Infection } \\
\text { Rate of } \\
\text { CVCA-BI** }\end{array}$ \\
\hline 2012 & 185 & 513 & 0.32 & 18.52 & 0.86 & 6.77 & 0.79 \\
2013 & 522 & 1746 & 0.23 & 12.38 & 0.87 & 0.66 & 0.75 \\
2014 & 504 & 2084 & 0.22 & 6.61 & 0.87 & 4.96 & 0.68 \\
2015 & 232 & 1081 & 0.27 & 7.07 & 0.91 & 6.29 & 0.75 \\
\hline
\end{tabular}

VAP: Ventilator-associated pneumonia; CA-UTI: Catheter-associated urinary tract infection; CVC: Central venous catheter; CVCA-BI: Central venous catheter-associated bloodstream infection; *Utilization rate: $100 \times$ (invasive instrument-associated infection / patient day);

**Infection rate: $100 \times$ (invasive instrument-associated infection / patient). 
Table 2. Quarterly distribution of invasive instrument-associated infection rates in 2014.

\begin{tabular}{|c|c|c|c|c|c|c|c|c|c|}
\hline Quarterly periods & $\begin{array}{l}\text { VAP } \\
\text { cases }\end{array}$ & $\begin{array}{c}\text { Ventilator } \\
\text { utilization } \\
\text { rate* }^{*}\end{array}$ & $\begin{array}{l}\text { Rate of } \\
\text { VAR** }\end{array}$ & $\begin{array}{c}\text { CA- } \\
\text { UTI } \\
\text { cases }\end{array}$ & $\begin{array}{c}\text { Urinary } \\
\text { catheter } \\
\text { utilization } \\
\text { rate* }\end{array}$ & $\begin{array}{c}\text { Rate of } \\
\text { CA- } \\
\text { UTI** }\end{array}$ & $\begin{array}{c}\text { CVCA- } \\
\text { BI } \\
\text { cases }\end{array}$ & $\begin{array}{c}\text { CVC } \\
\text { utilization } \\
\text { rate* }\end{array}$ & $\begin{array}{c}\text { Rate of } \\
\text { CVCR- } \\
\text { BI ** }\end{array}$ \\
\hline January-March & 2 & 0.24 & 8.20 & 3 & 0.88 & 4.47 & 0 & 0.64 & 0 \\
\hline April-June & 1 & 0.16 & 0.93 & 1 & 0.87 & 0.43 & 3 & 0.73 & 1.43 \\
\hline July-September & 0 & 0.20 & 0.00 & 1 & 0.89 & 0.66 & 2 & 0.70 & 0.93 \\
\hline October-December & 1 & 0.27 & 0.00 & 2 & 0.85 & 1.58 & 2 & 0.67 & 1.57 \\
\hline
\end{tabular}

VAP: Ventilator-associated pneumonia; CA-UTI: Catheter-associated urinary tract infection; CVC: Central venous catheter; CVCA-BI: Central venous catheter-associated bloodstream infection; *Utilization rate: $1000 \times$ (invasive instrument-associated infection / patient day); $* *$ Infection rate: $100 \times$ (invasive instrument-associated infection / patient).

initiated longer than 24 hours. The rate of inappropriate antibiotic prophylaxis was $72 \%$ according to the guideline of surgery prophylaxis of our hospital, despite active surveillance studies and continued education programs. In this context, one-to-one interviews with the surgeons were made and education programs were repeated.

It was observed that following the arrival of the patients in the operating theatre, skin preparation was performed with povidone iodine before the insertion of central venous catheter; however, the skin was wiped with a sponge without leaving the skin to dry for two minutes. The surgeons complied with surgical hand scrub time; however, hand-toweling practices were not appropriate. Some operating theatre personnel used surgical facemasks exposing their noses and the surgical team did not change their caps between operations. Some operating theater personnel spent some time out of the theater, while wearing surgical clothing, and then re-entered the operating room. During the cleaning between operations, infected materials were disposed of inappropriately, raising dust, and surfaces were wiped immediately following the application of disinfectant solutions, without leaving time for effective bacterial kill. The covering of the top mattress on the operating table was torn, exposing some areas of sponge beneath the covering. Samples were collected for culture from these exposed areas and the sterile materials frequently used during operations. No bacterial growth was observed in these cultures.

It was noted that, during visits to CVS-ICU, skin preparation prior to the insertion of the central venous catheter was performed with povidone iodine solution. The glass protection on the ceiling's lighting had been removed, on the grounds that the glass covering reduced the amount of light available. The personnel in the CVS-ICU did not wash or scrub their hands, preferring to use gloves rather than following hand hygiene practices. Equipment maintenance staff did not comply with infection barrier measures. Barrier methods and isolation measures were not followed in patients hospitalized in the intensive care unit, or in

Table 3. Distribution of microbiologic agents isolated from the infected patients during the study period.

\begin{tabular}{ccc}
\hline Agents & Number of infections (n) & Place of sampling \\
\hline P. aeruginosa & 2 & DTA, urine \\
S. maltophilia & 1 & Wound \\
K. pneumoniae & 2 & DTA, urine \\
A. baumanni & 1 & DTA \\
E. coli & 1 & Urine
\end{tabular}

DTA: Deep tracheal aspirate.

Table 4. Appropriate/inappropriate practices before and after surgery.

\begin{tabular}{|c|c|c|c|c|c|c|c|c|}
\hline \multirow[b]{2}{*}{ Practice } & \multicolumn{4}{|c|}{ Before surgery } & \multicolumn{2}{|c|}{ During surgery } & \multicolumn{2}{|c|}{ ICU } \\
\hline & Bathing & $\begin{array}{c}\text { Hair } \\
\text { removal }\end{array}$ & $\begin{array}{c}\text { Antibiotic } \\
\text { prophylaxis }\end{array}$ & $\begin{array}{c}\text { Skin } \\
\text { cleaning }\end{array}$ & $\begin{array}{c}\text { Surgical } \\
\text { hand scrub }\end{array}$ & $\begin{array}{c}\text { Room } \\
\text { cleaning } \\
\text { between the } \\
\text { operations }\end{array}$ & $\begin{array}{c}\text { Hand } \\
\text { hygiene }\end{array}$ & $\begin{array}{c}\text { Barrier and } \\
\text { isolation } \\
\text { measures }\end{array}$ \\
\hline Appropriate & & & + & + & + & & & \\
\hline Inappropriate & + & + & & & & + & + & + \\
\hline
\end{tabular}


patients requiring extensive debridement or emergency intervention. Table 4 shows the appropriateness of practices before, during and after surgery (Table 4).

Samples were collected from the surface of the operating table, sponge exposed from the torn portion of the mattress, sterile surgical materials frequently used during CVS procedure. No bacterial growth was observed in these cultures.

The report prepared after gathering this data was submitted to the hospital administration as well as to the department of cardiovascular surgery. Prompts and education programs were conducted about the control measures. Surveillance data were subsequently regularly monitored. A decrease has been noted in invasive instrument-associated infection rates following the implementation of the control measures and education programs (Table 2).

\section{Discussion}

Hospital-acquired infections remain one of the most important causes of mortality and morbidity. The mortality rate following cardiac surgery where there are complications with hospital-acquired infections is higher than that in cardiac surgery without such complications, showing a mortality rate ranging from $22 \%$ to $40 \%[8,9]$. On the basis of an increased incidence of health care-related infections in CVS-ICU, the present study showed the feasibility of reducing infection rates through various measures and the development of practices, as discussed below.

Previous studies have shown that deep sternal infections are the most critical infections patients can develop following cardiac surgery and elements of normal skin flora have been suggested as an important risk factor [3]. The studies suggest bathing with chlorhexidine-containing solutions in the morning on the day of surgery, as part of preoperative preparation, in order to prevent surgical site infections associated with endogenous flora $[10,11]$. Body hair should be removed using either a clipper or epilator; which both cause minimal skin abrasion $[12,13]$. On the other hand, there are also studies that suggest not removing body hair [14]. The established practice for patients' preparation is bathing in chlorhexidine-containing solutions before elective surgery; however, bath time was a night before the operation. In the CVS ward, patient body hair was shaved with a razor during preoperative preparation. The practices aimed at reducing surgical site infections were either missing or faulty and the nurse responsible and other nurses were provided with a repeated education program, emphasizing that the chlorhexidine-bath should be on the morning of the operation and the body must be shaved using the correct technique.

In accordance with the guidelines, patients undergoing cardiovascular surgery in the department of cardiovascular surgery are recommended prophylaxis with cefazolin $1 \mathrm{~g} 1$ hour before incision or vancomycin $1 \mathrm{~g}$ if the patient is allergic to cefazolin [15-17]. In contrast to our recommendations, it was noted that the patients received prophylaxic antibiotics from the time of admission and these antibiotics were continued throughout the hospital stay. Many studies found that the mode and duration of antibiotic prophylaxis was proportionate to the development of postoperative infections [3]. Inappropriate antibiotic prophylaxis is also known to increase health care costs and is associated with the development of bacterial resistance [18]. Antibiotic resistance rates in CVS-ICU are currently similar to general training and research hospital rates, as reported by the Health Ministry data in Turkey [19]. However, periodical education programs are being continued to raise awareness on appropriate antibiotic prophylaxis.

The literature often reports surgical site infections and cases of endocarditis following cardiac surgery $[20,21]$. Studies commonly report the control measures and postoperative infection rates of the hospital. The infection rates range from $0.50 \%$ to $10.34 \%$ with effective routine control measures [2,20]. Invasive device-related infections are preventable infections. The goal is to eliminate or reduce the invasive devicerelated infection rates by taking protection measures for all ICUs. On the other hand, studies in the literature did not examine prediction of an outbreak and measures taken during the acute phase of an outbreak.

The present study did not find an outbreak arising from a single microorganism in the CVS-ICU but rather one caused by multiple microorganisms. High-risk patients underwent simultaneous operations during our assessment in CVS-ICU. Therefore, these patients had prolonged stays in the hospital. The increase in the length of stay correlated with an increase in invasive instrument-related infections. The education of all the personnel in charge of the CVS ward, intensive care unit, and operating room, was reiterated on hand hygiene, instrumentation and the maintenance of invasive devices. There was no specific prevalence in the microorganisms isolated from the patients. Therefore, it was not possible to refer to the situation as an outbreak. However, the implementation of sustainable infection control measures, particularly in departments such as in CVS ICU, is required in order to prevent outbreaks, predict imminent threats, and 
perform early intervention. The effective measures taken in the present study, and the continued education of each and every health care worker, prevented a possible outbreak and reduced the invasive instrumentrelated infection rate. In our study; frequent repetition of clinical visits and trainings, increased awareness of infection control measures and improved cooperation with all employees has reduced instrument-related infection rates. With the measures taken after the first three months of 2014, VAP rates dropped to zero. Invasive device-associated infections are the preventable infections and this can be achieved by continuing education and increasing compliance with control measures.

\section{Conclusion}

Despite the availability of new and effective antibiotics, bacterial resistance to many antibiotics is a challenge in the treatment of infections, particularly in intensive care units. Infection control measures must be established in specialized departments, such as in CVSICU, in order to prevent infections. The presence of a properly and effectively working infection control committee would ensure the establishment of the required measures, and prevent outbreaks as soon as the risk of one is apparent.

\section{References}

1. Baghaei R, Mikaili P, Nourani D, Khalkhali HR (2011) An epidemiological study of nosocomial infections in the patients admitted in the intensive care unit of Urmia Imam Reza Hospital: An etiological investigation. Ann Biol Res 2: 172178.

2. Finkelstein R, Rabino G, Mashiah T, Bar-El Y, Adler Z, Kertzman V, Cohen O, Milo S (2005) Surgical site infection rates following cardiac surgery: The impact of a 6-year infection control program. Am J Infect Control 33: 450-454.

3. Gelijns AC, Moskowitz AJ, Acker MA, Argenziano M, Geller NL, Puskas JD, Perrault LP, Smith PK, Kron IL, Michler RE, Miller MA, Gardner TJ, Ascheim DD, Ailawadi G, Lackner P, Goldsmith LA, Robichaud S, Miller RA, Rose EA, Ferguson TB Jr, Horvath KA, Moquete EG, Parides MK, Bagiella E, O'Gara PT, Blackstone EH (2014) Management practices and major infections after cardiac surgery. J Am Coll Cardiol 64: 372-381.

4. Kendall JB, Hart CA, Pennefather SH, Russell GN (2003) Infection control measures for adult cardiac surgery in the UK - a survey of current practice. J Hosp Infect 54: 174-178.

5. Haas JP, Evans AM, Preston KE, Larson EL (2005) Risk factors for surgical site infection after cardiac surgery: The role of endogenous flora. Heart Lung 34: 108-114.

6. Segers P, de Jong AP, Kloek JJ, Spanjaard L, de Mol BAJM (2006) Risk control of surgical site infection after cardiothoracic surgery. J Hosp Infect 62: 437-445.

7. Leaper D, Ousey K (2015) Evidence update on prevention of surgical site infection. Curr Opin Infect Dis 28: 158-163.

8. Hollenbeak CS, Murphy DM, Koening S, Woodward RS, Dunagan WC, Fraser VJ (2000) The clinical and economic impact of deep chest surgical site infections following coronary artery bypass graft surgery. Chest 118: 397-402.

9. Jenney AWJ, Harrington GA, Russo PL, Spelman DW (2001) Cost of surgical site infections following coronary artery bypass surgery. ANZ J Surg 71: 662-664.

10. Bode LGM, Kluytmans JAJW, Wertheim HFL, Bogaers D, Vandenbroucke-Grauls CMJE, Roosendaal R, Troelstra A, Box ATA, Voss A, van der Tweel I, van Belkum A, Verbrugh HA, Vos MC (2010) Preventing surgical-site infections in nasal carriers of Staphylococcus aureus. N Engl J Med 362: 917.

11. Webster J, Osborne S (2015) Preoperative bathing or showering with skin antiseptics to prevent surgical site infection. Cochrane Database Syst Rev 2: CD004985.

12. Kjonniksen I, Andersen BM, Sondenaa VG, Segadal L (2002) Preoperative hair removal: a systematic literature review. AORN J 75: 928-940.

13. Alexander JW, Fischer JE, Boyajian M, Palmquist J, Morris MJ (1983) The influence of hair-removal methods on wound infections. Arch Surg 118: 347-352.

14. Mangram AJ, Horan TC, Pearson ML, Silver LC, Jarvis WR (1999) Guideline for prevention of surgical site infection, 1999. Infect Control Hosp Epidemiol 20: 247-278.

15. Bratzler DW, Dellinger EP, Olsen KM, Perl TM, Auwaerter PG, Bolon MK, Fish DN, Napolitano LM, Sawyer RG, Slain D, Steinberg JP, Weinstein RA (2013) Clinical practice guidelines for antimicrobial prophylaxis in surgery. Am J Health-Syst Pharm 70: 195-283.

16. Engelman R, Shahian D, Shemin R, Guy TS, Bratzler D, Edwards F, Jacobs M, Fernando H, Bridges C (2007) The Society of Thoracic Surgeons practice guideline series: 
Antibiotic prophylaxis in cardiac surgery, Part II; Antibiotic choice. Ann Thorac Surg 83: 1569-1576.

17. Edwards FH, Engelman RM, Houck P, Shahian DM, Bridges CR (2006) The Society of Thoracic Surgeons practice guideline series: Antibiotic prophylaxis in cardiac surgery, Part I; Duration. Ann Thorac Surg 81: 397-404.

18. Bevilacqua S, Demoré B, Boschetti E, Doco-Lecompte T, May I, May T, Rabaud C, Thilly N (2011) 15 years of antibiotic stewardship policy in the Nancy Teaching Hospital. Med Mal Infect 41: 532-539.

19. Çetinkaya Şardan Y, Callak Oku F, Bartır E, Kabasaka E, Doluküp İ, Kösekahya A (2016) Turkish Government Ministry of Health, Summary Report on National Hospital Infections. Available:

https:/www.researchgate.net/publication/322854736_ULUS AL_HASTANE_ENFEKSIYONLARI_SURVEYANS_AGI_ OZET_RAPORU_2016. Accessed 10 September 2017.

20. Gelijns AC, Moskowitz AJ, Acker MA, Argenziano M, Geller NL, Puskas JD, Perrault LP, Smith PK, Kron IL, Michler RE, Miller MA, Gardner TJ, Ascheim DD, Ailawadi G, Lackner P,
Goldsmith LA, Robichaud S, Miller RA, Rose EA, Ferguson TB Jr, Horvath KA, Moquete EG, Parides MK, Bagiella E, O'Gara PT, Blackstone EH (2014) Management practices and major infections after cardiac surgery. J Am Coll Cardiol 64: 372-381.

21. Seyman D, Inan D, Ozen NS, Ogunc D (2014) An outbreak of Pseudomonas aeruginosa infective endocarditis subsequent to coronary angiography. Rev Chilena Infectol 31: 261-267.

\section{Corresponding author}

Dr. Esra Kaya Kiliç, MD

Department of Infectious Diseases and Clinical Microbiology Ankara Training and Research Hospital,

Sukriye District Ulucanlar Street 06230, Altindag, Ankara, Turkey Phone: +903125954011

Email: esrakayakilic@yahoo.com.tr

Conflict of interests: No conflict of interests is declared. 